\title{
INFORMASI BIOLOGI PERIKANAN IKAN KURISI, Nemipterus japonicus, DI BLANAKAN DAN TEGAL
}

\author{
Indar Sri Wahyuni, Sri Turni Hartati, dan Ina Juanita Indarsyah \\ Peneliti pada Balai Riset Perikanan Laut, Muara Baru-Jakarta \\ Teregistrasi I tanggal: 18 September 2007; Diterima setelah perbaikan tanggal: 16 Januari 2008; \\ Disetujui terbit tanggal: 12 Januari 2009
}

\begin{abstract}
ABSTRAK
Berbagai jenis ikan kurisi (Nemipteridae) termasuk Nemipterus japonicus, merupakan jenis ikan demersal yang banyak tertangkap dengan cantrang (jaring dogol), bertubuh relatif kecil dan berenang secara bergerombol (schooling) serta banyak ditemukan pada kedalaman 25-40 m. Pengamatan ikan kurisi difokuskan pada $N$. japonicus dan dilakukan di daerah Blanakan (Subang, Jawa Barat) dan daerah Tegal (Jawa Tengah) mulai Maret-April 2006. Di Blanakan, hasil tangkapan ikan kurisi berkisar $2-10,7 \%$ dari total hasil tangkapan cantrang besar maupun kecil dan di Tegal $15-35 \%$. Struktur ukuran (sebaran panjang) ikan kurisi di Blanakan pada bulan Januari 2006 didominansi oleh ukuran $10 \mathrm{~cm}$ pada bulan Pebruari dan Maret 2006 didominansi oleh ukuran 12 dan $16 \mathrm{~cm}$, sedangkan bulan April 2006 didominansi oleh ukuran 10,5 cm. Struktur ukuran ikan kurisi di Tegal didominansi ukuran $11,45 \mathrm{~cm}$ yaitu $21,2 \%$. Tingkat kematangan gonad ikan kurisi di Blanakan didominansi III yaitu 19,3\%; sedangkan di Tegal didominansi oleh tingkat $V$ (spent) yaitu 34,8\%. Isi perut ikan kurisi di Blanakan dan Tegal relatif sama, yaitu di dominansi oleh Polychaeta, Bacillariophyceae, dan Crustaceae. Pertumbuhan ikan kurisi bersifat allometrik $(b<3,0)$.
\end{abstract}

KATAKUNCl: $\quad$ ikan kurisi, Nemipterus japonicus, sebaran panjang, tingkat kematangan gonad, kebiasaan makan

\section{PENDAHULUAN}

Berbagai jenis ikan kurisi (Nemipteridae) termasuk ikan dasar (demersal), banyak tertangkap dengan menggunakan cantrang atau payang. Jenis alat ini banyak dioperasikan di perairan utara Jawa setelah adanya larangan penggunaan jaring trawl. Ada beberapa jenis ikan kurisi, namun jenis yang banyak didaratkan di Blanakan dan Tegal adalah jenis Nemipterus japonicus. Meskipun tubuhnya tidak terlalu besar, ikan kurisi banyak ditemukan di daerah pesisir dengan dasar berlumpur atau berpasir pada kedalaman 5 - $80 \mathrm{~m}$. Populasi ikan kurisi kecil pada umumnya melimpah pada kedalaman $<27 \mathrm{~m}$, dan hanya ikan-ikan berukuran agak besar ditemukan pada kedalaman >45 m (Eggleston, 1973 dalam Russell, 1990).

Hasil tangkapan ikan kurisi yang melimpah serta harganya yang relatif murah telah menarik pengusaha perikanan untuk mengolah ikan tersebut menjadi bahan olahan seperti surimi. Menurut Russell (1990), ikan kurisi banyak dipasarkan dalam bentuk segar, dikukus (steam) atau dibuat baso ikan (fish ball).

Aoyama (1973) dalam Widodo (1991) mengatakan bahwa ikan demersal bersifat antara lain:

1. Membentuk gerombolan yang tidak terlalu besar.

2. Rekruitmennya banyak bervariasi karena di dukung oleh kondisi lingkungan yang relatif stabil.
3. Melakukan ruaya yang tidak terlalu jauh.

4. Aktivitas geraknya relatif rendah.

Dua sifat terakhir tersebut mengakibatkan daya tahan ikan-ikan demersal terhadap tekanan penangkapan menjadi rendah. Tulisan ini menyajikan beberapa data aspek biologi ikan kurisi (Nemipterus japonicus) yang dapat dipergunakan sebagai informasi awal tentang kondisi ikan kurisi tersebut di perairan utara Jawa.

Pengambilan contoh ikan dilakukan di daerah Blanakan (Subang, Jawa Barat) mulai Januari-April 2006 dan Tegal (Jawa Tengah) mulai Maret- April 2006. Contoh ikan kurisi diperoleh dari hasil tangkapan nelayan cantrang yang didaratkan di Tempat Pandaratan Ikan (TPI) Blanakan, dan TPI Tegal Sari, Tegal. Aspek biologi yang diamati meliputi panjang dan bobot, tingkat kematangan gonad, dan isi perut. Identifikasi jenis berpedoman pada F.A.O. (Russell, 1990). Hubungan panjang dan bobot ikan mengikuti rumus Hille (1936) dalam Effendie (1997):

$$
W=C L^{n}
$$

di mana :

$$
\begin{array}{ll}
\mathrm{W} & =\text { bobot ikan }(\mathrm{g}) \\
\mathrm{L} & =\text { panjang } \mathrm{ikan}(\mathrm{cm}) \\
\mathrm{C} \text { dan } \mathrm{n} & =\text { konstanta }
\end{array}
$$


Tingkat kematangan gonad ditentukan berdasarkan kriteria Nikolsky (Bagenal \& Braum, 1968 dalam Effendie, 1979). Analisis isi perut ikan menggunakan metode Index of Preponderance (Natarajan \& Jhingran, 1961 dalam Effendie, 1979):

$$
\mathrm{IP}=\frac{(\mathrm{VixOi})}{\Sigma(\mathrm{Vi} \times \mathrm{Oi})} \times 100 \%
$$

di mana:

$$
\begin{array}{ll}
\mathrm{Vi} & =\text { volume } 1 \text { jenis makanan }(\%) \\
\mathrm{Oi} & =\text { frekuensi kejadian } 1 \text { jenis makanan }(\%) \\
\Sigma(\mathrm{VixOi})= & \text { jumlah VixOi dari semua jenis } \\
& \text { makanan } \\
\mathrm{IP} \quad= & \text { index of Preponderance }
\end{array}
$$

\section{HASIL TANGKAPAN}

Ikan kurisi yang diamati merupakan hasil tangkapan cantrang. Seperti halnya fish net, cantrang dioperasikan pada perairan yang relatif dalam 30-35 $\mathrm{m}$. Nelayan cantrang di daerah Blanakan beroperasi di perairan Pulau Bangka, Pulau Belitung, dan Selat Karimata, sedang nelayan cantrang Tegal beroperasi di perairan Brebes, Suradadi, sampai Cirebon ke arah timur, daerah operasinya mencapai perairan selatan Pulau Kalimantan, di perairan Masalembo, Mata Siri, Tanjung Selatan, sampai ke Pulau Kangean. Proporsi

\begin{tabular}{|c|c|c|c|}
\hline \multirow{2}{*}{ No. } & \multirow{2}{*}{ Jenis/Spesies } & \multicolumn{2}{|c|}{ Komposisi dalam bobot (\%) } \\
\hline & & Kapal 1 & Kapal 2 \\
\hline 1. & Kakap merah (Lutjanus malabaricus) & 3,00 & - \\
\hline 2. & Kerapu Epinephelus sp.) & 2,00 & - \\
\hline 3. & Coklatan (Scolopsis sp.) & 20,00 & 17,86 \\
\hline 4. & Cumi-cumi (Loligo sp.) & 15,00 & - \\
\hline 5. & Pari Dasyatis sp.) & 10,00 & 7,14 \\
\hline 6. & Petek (Leiognathus sp.) & 10,00 & 5,36 \\
\hline 7. & Manyung (Arius sp.) & 7,00 & 8,93 \\
\hline 8. & Ekor kuning (Lutjanus vittus) & 3,00 & 3,57 \\
\hline 9. & Demang (Priacanthus tayenus) & 2,00 & 14,29 \\
\hline 10. & Utik (Arius sp.) & 3,00 & - \\
\hline 11. & Beloso (Saurida sp.) & 4,00 & 7,14 \\
\hline 12. & Selar (Selaroides leptolepis) & 2,00 & 3,57 \\
\hline 13. & Kuniran (Upeneus sp.) & 8,00 & \\
\hline 14. & Ayam-ayam (Abalistes stellatus) & 4,00 & 8,93 \\
\hline 15. & Kurisi (Nemipterus japonicus) & 2,00 & 10,71 \\
\hline 16. & Bentong (Selar crumenophthalmus) & 2,00 & - \\
\hline 17. & Kapasan Pentaprion longimanus) & 3,00 & - \\
\hline 18. & Sebelah (Cynoglossus sp.) & - & 5,36 \\
\hline 19. & Alu-alu Sphyraena sp.) & - & 3,57 \\
\hline 20. & Gerot-gerot (Diagramma punctatum) & - & 3,57 \\
\hline & Total & 100 & 100 \\
\hline
\end{tabular}
hasil tangkapan ikan kurisi dengan ikan lainnya dari hasil tangkapan cantrang di Blanakan (Subang) tercantum pada Tabel 1.

Tabel 1.

Komposisi hasil tangkapan cantrang di perairan Blanakan, Subang, tahun 2006

Di daerah Blanakan, hasil tangkapan ikan kurisi berkisar $2,0-10,7 \%$ dari total hasil tangkapan ikan. Sedangkan di Tegal, dioperasikannya alat tangkap cantrang besar dan kecil yang masing-masing berbeda ukuran alat dan daerah operasinya, hasil tangkapan ikan kurisi dari alat tangkap cantrang kecil adalah $15 \%$ dari total hasil tangkapan yang jumlahnya $1-2$ ton. Hasil tangkapan cantrang besar mencapai 35\% dari total hasil tangkapan yang jumlahnya 10 - 40 ton (Tabel 2). Weber \& Jothy (1977) mengatakan bahwa di perairan Serawak dan Sabah, hasil tangkapan ikan kurisi adalah terbanyak (31\%) di antara hasil tangkapan ikan kurisi lainnya seperti $N$. mesoprion $(24,5 \%), N$. bleekeri $(1,8 \%), N$. delagoae $(1,6 \%), N$. nemurus $(1,4 \%)$, dan Nemipterus sp. $(0,7 \%)$.

\section{SEBARAN UKURAN PANJANG}

Data yang terkumpul menunjukkan bahwa sebaran ukuran panjang cagak ikan kurisi pada bulan Januari 2006 di perairan Blanakan didominansi oleh ukuran nilai tengah $10 \mathrm{~cm}$. Nilai ini pada bulan Pebruari 2006 bergeser ke 12,0 cm, kemudian pada bulan Maret bergeser ke $16,0 \mathrm{~cm}$. Pada bulan April 2006, 
ukurannya didominansi oleh $10,5 \mathrm{~cm}$. Kondisi ini memperlihatkan bahwa setiap bulan terdapat perbedaan cohort ikan kurisi yang didaratkan. Sebaran ukuran panjang ikan kurisi di daerah Tegal didominansi oleh ukuran $11,45 \mathrm{~cm}$, yaitu $21,2 \%$ dari total ikan contoh. Menurut Russell (1990), panjang baku maksimum ikan kurisi di perairan Laut Cina Selatan adalah $25 \mathrm{~cm}$, sedangkan panjang baku pada umumnya $15 \mathrm{~cm}$. Di perairan Laut Cina Selatan, ikan kurisi betina adalah dominan pada ukuran muda (kecil), sedangkan ikan kurisi jantan pada ukuran besar, karena pertumbuhan rata-rata ikan jantan jauh lebih cepat (Lee, 1974 dalam Russell, 1990).

Dari hasil perhitungan data persentase kumulatif tingkat kematangan gonad ikan kurisi di Blanakan dapat diketahui bahwa pada bulan Januari 2006, ikan kurisi pertama kali matang gonad berukuran $9 \mathrm{~cm}$, sedangkan pada bulan Pebruari 2006, berukuran 11 $\mathrm{cm}$. Pada bulan Maret, ikan kurisi matang gonad berukuran 12,5 cm, sedangkan pada bulan April 2006, berukuran $9,5 \mathrm{~cm}$ (Gambar 1). Hasil pengamatan di daerah Tegal menunjukkan bahwa ikan kurisi pertama kali matang gonad berukuran 12,5 cm (Gambar 2).

Kenyataan ini menunjukkan bahwa ukuran ikan kurisi yang memijah pertama kali adalah $12,5 \mathrm{~cm}$. Krishnamoorthi (1971) dalam Said (1987) mengatakan bahwa di perairan Andhra Orissa (India), N. japonicus betina mencapai ukuran pertama kali matang gonad pada ukuran $16,5 \mathrm{~cm}$. la juga mengatakan bahwa ikan kurisi tersebut melakukan spawning mulai September -Nopember. Sedangkan jenis N. mesoprion, mencapai pertama kali memijah pada ukuran 10,0 cm (Murty, 1983 dalam Said, 1987).

Jika dibandingkan dengan hasil pengamatan di Blanakan dan Tegal, ikan kurisi yang diamati oleh Krishnamoorthi (1971) dalam Said (1987) memiliki ukuran pertama kali matang gonad lebih besar. Hal ini diduga karena tekanan penangkapan yang terjadi di perairan India tidak seberat seperti di perairan utara Jawa.

Tabel 2. Komposisi hasil tangkapan kapal cantrang besar dan kecil di perairan Tegal, Jawa Tengah

\begin{tabular}{|c|c|c|}
\hline \multirow{2}{*}{ Spesies } & \multicolumn{2}{|c|}{ Komposisi dalam bobot(\%) } \\
\hline & Cantrang besar & Cantrang kecil \\
\hline Coklatan (Scolopsis sp.) & 40,82 & - \\
\hline Kurisi (Nemipterus japonicus) & 35,71 & 14,29 \\
\hline Ayam-ayam (Abalistes stellatus) & 5,10 & - \\
\hline Pari (Dasyatis sp.) & 2,04 & 9,52 \\
\hline Demang (Priacanthus tayenus) & 5,10 & - \\
\hline Kuniran (Upeneus sp.) & 3,06 & - \\
\hline Katep & 5,10 & - \\
\hline Buntal (Tetraodon sp.) & 3,06 & 9,52 \\
\hline Kurisi (Nemipterus japonicus) & - & - \\
\hline Cumi-cumi (Loligo sp.) & - & 23,81 \\
\hline Galet & - & 4,76 \\
\hline Loang(Stromateus sp.) & - & 6,67 \\
\hline Layur (Trichiurus sp.) & - & 7,62 \\
\hline Selar (Selaroides leptolepis) & - & 14,29 \\
\hline Teri (Stolephorus sp.) & - & 9,52 \\
\hline Total & 100 & 100 \\
\hline
\end{tabular}

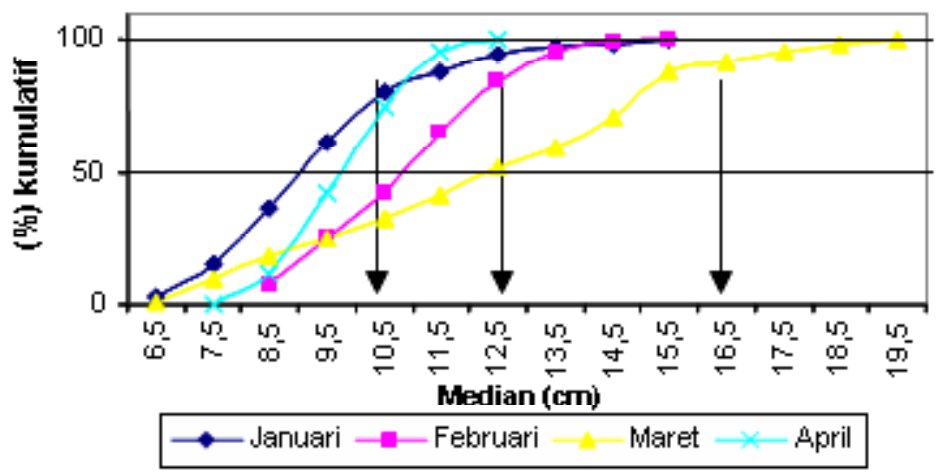

Gambar 1. Persentase kumulatif ikan kurisi, N. japonicus, di Blanakan, Januari - April 2006. 


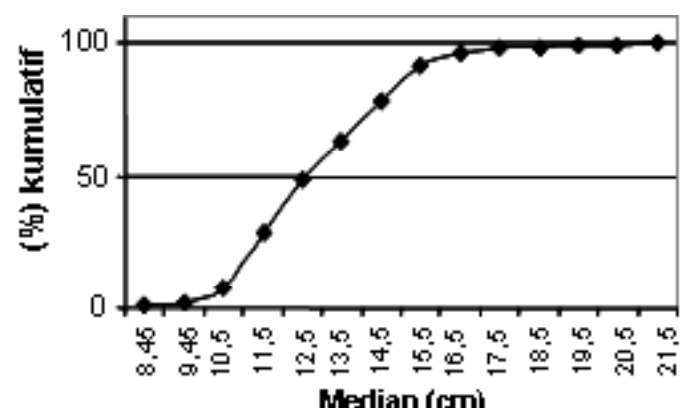

Gambar 2. Persentase kumulatif ikan kurisi, N. japonicus, di Tegal, April 2006.

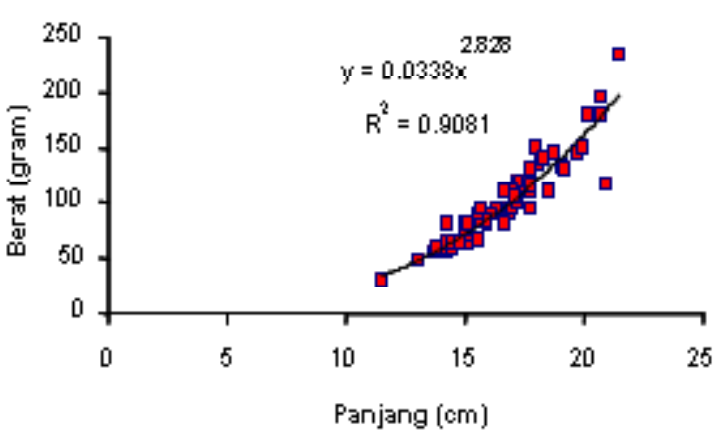

(Blanakan)

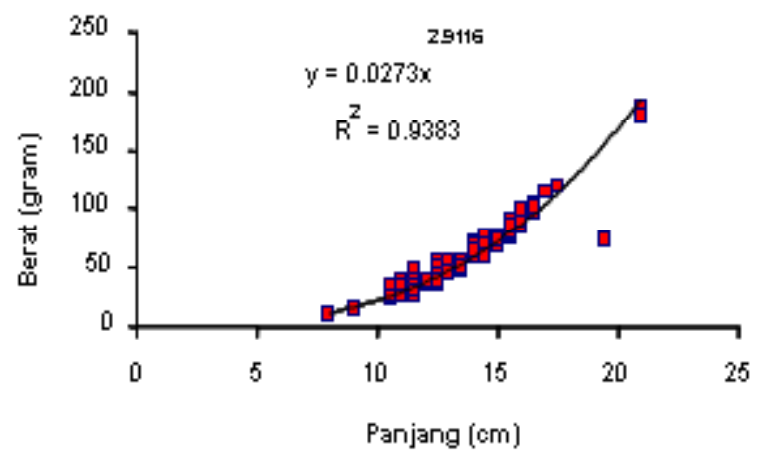

(Tegal)

Gambar 3. Hubungan panjang bobot ikan kurisi, N. japonicus, di Blanakan dan Tegal, April 2006.

\section{ANALISIS PANJANG BOBOT}

Hasil analisis hubungan panjang bobot yang dilakukan terhadap contoh ikan kurisi dari Blanakan dan Tegal diperoleh masing-masing persamaan regresi sebagai berikut (Gambar 3):

$$
\begin{aligned}
& \mathrm{Y} 1=0,0338+2,828 \times \ldots . \\
& \mathrm{R}^{2}=0,9081 \\
& \mathrm{~b}=2,828 ; \mathrm{n}=67 \text { ekor } \\
& \mathrm{Y} 2=0,0273+2,9116 \times \ldots \\
& \mathrm{R}^{2}=0,9383 \\
& \mathrm{~b}=2,9116 ; \mathrm{n}=136 \text { ekor }
\end{aligned}
$$

Dari perhitungan diperoleh nilai pertumbuhan ikan (b) adalah $<3,0$; berarti bahwa pertumbuhan ikan bersifat allometrik positif, di mana pertambahan panjang lebih cepat dari pertambahan bobot, ikan jadi nampak lebih panjang atau kurus (Effendie, 1997).

\section{TINGKAT KEMATANGAN GONAD}

Hasil pengamatan tingkat kematangan gonad 62 ekor contoh ikan kurisi di Blanakan menunjukkan bahwa 42 ekor adalah ikan betina yang mempunyai tingkat kematangan gonad (TKG) I - VI yang didominansi oleh TKG III (12 ekor, 19,35\%). TKG V dan VI masing-masing berjumlah 5 dan 3 ekor. Selanjutnya, 15 ekor ikan kurisi adalah jantan yang memiliki TKG II (7 ekor), III (4 ekor), dan IV (4 ekor). Dengan demikian dapat dikatakan bahwa ikan kurisi matang gonad di Blanakan pada bulan Maret 2006 mulai berkurang jumlahnya (Tabel 3 ).

Hasil pengamatan terhadap 138 ekor contoh ikan kurisi di Tegal menunjukkan bahwa 48 ekor (34,8\%) telah matang gonad (mijah), yaitu memiliki TKG V, sedangkan 89 ekor $(64,5 \%)$ tidak teridentifikasi dan hanya 1 ekor ikan jantan dengan TKG III. Dengan demikian dapat dikatakan bahwa sebagian besar ikan kurisi di Tegal pada bulan Maret 2006 dalam keadaan siap untuk memijah (Tabel 4).

Waktu pemijahan ikan kurisi di Andra Orissa dan Tegal-Blanakan berbeda, disebabkan oleh perbedaan ukuran ikan tersebut. Ikan kurisi Tegal dan Blanakan berukuran lebih kecil sehingga cepat matang gonad, di Andra Orissa, ukurannya lebih besar (lambat matang gonadnya).

Ikan kurisi cenderung memijah dalam periode panjang. Di Laut Cina Selatan, ikan ini memijah mulai bulan Mei - Oktober (Eggleston, 1972). Menurut Webber \& Jothy (1977), di perairan Malaysia Timur, 
pemijahannya terjadi mulai Nopember- Pebruari, di India mulai bulan Agustus - April (Murty, 1984 dalam Russell, 1990).

\section{ANALISIS ISI PERUT}

Analisis isi perut ikan kurisi dari Blanakan dan Tegal pada April 2006 menunjukkan hasil relatif sama, masing-masing didominansi oleh Polychaeta dengan nilai Index of Preponderance (IP) 42,2 - 50,1\%, kemudian disusul oleh Bacillariophyceae dengan nilai IP 27,3 - 30,7\%, dan krustasea IP 15,2 - 19,8\%. Di samping itu, terdapat fitoplankton dari Chrysophyceae dan Dinophyceae, serta zooplankton seperti Cilliata dan Sarcodina dengan masing-masing nilai IPnya $0,01-1,95 \%$.

Isi perut ikan kurisi dari Blanakan terdapat zooplankton (Aschelminthes, Molusca, Cilliata, dan Sarcodina) dan phytoplankton (jenis Chlorophyceae dan Dinophyceae). Komposisi isi perut ikan kurisi dari masing-masing lokasi tercantum pada Tabel 5.
Makanan ikan kurisi dari perairan India dan Laut Cina Selatan terdiri atas ikan-ikan kecil, Krustase, Molluska (khusus Cephalophoda), Polychaeta, dan Echinodermata (Russell, 1990). Dengan demikian, dapat dikatakan bahwa makanan ikan kurisi di utara Jawa lebih beragam.

$N$. japonicus di perairan Andhra Orissa bersifat karnivora, predator aktif, dan memakan binatang apa saja yang bergerak (Krisnamoorthi, 1971 dalam Said, 1987). Ikan ini memakan cumi-cumi sepanjang tahun dan puncak musimnya pada bulan Maret dan Agustus. Cumi-cumi dan udang-udangan memiliki hubungan terbalik dengan kepiting, apabila jumlah udangudangan pada lambung ikan itu rendah, maka jumlah kepiting di perairan akan tinggi.

Menurut Eggleston (1972) dalam Said (1987), N. japonicus merupakan predator aktif. Sebagian besar makanannya terdiri atas Crustaceae, ikan, dan Cephalopoda. Selanjutnya, ikan ini memakan lebih banyak Lamelibranch moluska, dibandingkan yang lainnya. Waktu makannya adalah pada siang hari.

Tabel 3. Tingkat kematangan gonad ikan kurisi, N. japonicus, di Blanakan, Maret 2006

\begin{tabular}{ccccccccc}
\hline \multirow{2}{*}{ Jenis kelamin } & \multicolumn{9}{c}{ Tingkat kematangan gonad } & \multicolumn{2}{c}{ Jumlah } \\
\cline { 2 - 7 } & I & II & III & IV & V & VI & 42 \\
Betina & 8 & 7 & 12 & 7 & 5 & 3 & 15 \\
Jantan & - & 7 & 4 & 4 & - & - & 5 \\
Tidak teridentifikasi & - & - & - & - & - & - & 5 \\
\hline
\end{tabular}

Tabel 4. Tingkat kematangan gonad ikan kurisi, N. japonicus, di Tegal, Maret 2006

\begin{tabular}{ccccccccc}
\hline \multirow{2}{*}{ Jenis kelamin } & \multicolumn{9}{c}{ Tingkat kematangan gonad } & \multirow{2}{*}{ Jumlah } \\
\cline { 2 - 7 } & I & II & III & IV & V & VI & 48 \\
Betina & - & - & - & - & 48 & - & 1 \\
Jantan & - & - & 1 & - & - & - & - & 89 \\
Tidak teridentifikasi & - & - & - & - & - & - & \\
\hline
\end{tabular}

Tabel 5.

Komposisi makanan ikan kurisi, N. japonicus, dari di Blanakan dan Tegal, April 2006

\begin{tabular}{|c|c|c|c|c|}
\hline \multirow{2}{*}{ No. } & \multirow{2}{*}{ Jenis makanan } & \multicolumn{2}{|c|}{ Index of Preponderance (\%) } & \multirow{2}{*}{ Keterangan } \\
\hline & & Blanakan & Tegal & \\
\hline 1. & Polychaeta & 42,23 & 50,10 & Dominan \\
\hline 2. & Bacillariophyceae & 30,68 & 27,27 & Dominan \\
\hline 3. & Crustaceae & 15,16 & 19,78 & Dominan \\
\hline 4. & Sarcodina & 7,2 & 1,95 & \\
\hline 5. & Dinophyceae & 4,29 & 0,57 & \\
\hline 6. & Chrysophyceae & 0,01 & 0,01 & \\
\hline 7. & Aschelminthes & 0,01 & 0 & \\
\hline 8. & Ciliata & 0,3 & 0,06 & \\
\hline 9. & Fish & 0,1 & 0 & \\
\hline 10. & Molusca & 0,02 & 0 & \\
\hline \multirow[t]{2}{*}{11.} & Larva Cephalopoda & 0 & 0,26 & \\
\hline & Total & 100 & 100 & \\
\hline
\end{tabular}




\section{KESIMPULAN}

1. Di Blanakan ikan kurisi, Nemipterus japonicus, pertama kali matang gonad pada ukuran 9,0 - 12,5 $\mathrm{cm}$, sedangkan di Tegal $12,5 \mathrm{~cm}$.

2. Isi perut ikan kurisi dari Blanakan dan Tegal adalah relatif sama, didominansi oleh Polychaeta dengan nilai Index of Preponderance 42,23 - 50,10\%, dan diikuti oleh Bacillariophyceae (27,3 - 30,7\%) dan Krustase (15,2 - 19,8\%).

3. Pertumbuhan ikan kurisi bersifat allometrik positif $(b<3,0)$, berarti pertambahan panjang ikan lebih cepat dibandingkan pertambahan bobotnya.

\section{PERSANTUNAN}

Kegiatan dari hasil riset pengkajian stok, life history, dan dinamika populasi sumber daya ikan demersal dan udang penaeid di Laut Cina Selatan, Laut Jawa, dan Selat Makassar, T. A. 2006, di Balai Riset Perikanan Laut, Muara Baru-Jakarta.

\section{DAFTAR PUSTAKA}

Effendie, M. I. 1979. Metode Biologi Perikanan. Penerbit Dewi Sri. Bogor. 109 pp.

1997. Biologi Perikanan. Yayasan Pustaka Nusantara. Yogyakarta. 161 pp.
Russell, B. C. 1990. F. A. O. Species Catalogue. Vol. 12. Nemipterid Fishes of the World (Thredfin Breams, Whiptail Breams, Monocle Breams, Dwarf Monocle Breams, and Coral Breams) Family Nemipteridae an Annotated and Illustrated Catalogue of Nemipterid Species Known to Date. FAO. Fisheries Synopsis. No.125 Vol.12. FAO. of the United Nation. Rome. 149 pp.

Said, M. M. Z. 1987. A study on the biology and fisheries of threadfin bream (Nemipteridae) with special reference to $N$. peronii caught in water of the Trenggano Coast. A Thesis Submitted in Partial Fulfilment of the Requirements for the Degree of Doctor of Philosophy in the Fac. of Fisheries and Marine Science. University of Agriculture Malaysia.

Udupa, K. S. 1986. Statistical method of estimating the size at first maturity in fishes. University of Agricultural Sciences. Collage of Fisheries Mengalore. India. Fishery Byte. 8-10.

Weber, W. \& Jothy, A. A. 1977. Observation on the Fish Nemipterus spp. (Nemipteridae) in the Coastal Waters of East Malaysia. Arch Fish Wiss. 28. 2/ 3 December 1917. Berlin. 109-122.

Widodo, J. 1991. Petunjuk Teknis Pemanfaatan dan Pengolahan Beberapa Spesies Sumber Daya Ikan Demersal Ekonomis Penting. Seri Pengembangan Hasil Penelitian dan Pengembangan No.PHP/ KAN16/191. Jakarta. 